\title{
Properties and anisotropy behaviour of a nickel base alloy material produced by robot-based wire and arc additive manufacturing
}

\author{
Thomas Hassel $^{1}$ (D) Torben Carstensen $^{1}$ (D) \\ Received: 26 November 2019 / Accepted: 17 July 2020 / Published online: 24 July 2020 \\ (C) The Author(s) 2020
}

\begin{abstract}
In order to produce three-dimensional components from metals, a wide variety of processes exist. Laser processes combined with metal powders are frequently used and developed. Restrictive factors are the machine-related small workspace, the machinery costs and the material portfolio, which place the technology in the area of high-performance components. Wire and arc additive manufacturing (WAAM), as a robust and economical welding process technology in combination with robot applications, represents an option to become more size-independent and provides variability in the range of materials. This work shows results for the robot-based WAAM of structures made from nickel alloy 617 . The main focus of the investigation was the determination of the mechanical properties in the as-welded state for which static strength tests, microhardness and metallographic studies were carried out. The anisotropic material behaviour in relation to the build direction (BD) was tested. The direction-dependent strength properties of single-track welded structures are presented with samples taken and tested at $0^{\circ}, 45^{\circ}$ and $90^{\circ}$ to the BD. The deformation behaviour was investigated by micro-tensile tests in a scanning electron microscope, whereby the formation of sliding steps on the polished surface under tensile stress was studied. The anisotropic behaviour of the WAAM structures is discussed under consideration of the microstructure and with regard to the grain size development and phase formation. The results indicate an anisotropic material behaviour in the as-welded state based of the crystallographic orientation of the material.
\end{abstract}

Keywords WAAM $\cdot$ Anisotropy $\cdot$ Additive manufacturing $\cdot$ Nickel alloys $\cdot$ Properties $\cdot$ Inconel

\section{Introduction}

Forecasts for additive manufacturing's (AM) global market volume until 2024 show an annual growth rate of approximately $20 \%$ [1]. AM is at its turning point moving from the rapid prototyping sector into mass production. This change is due to the advantages of additive manufacturing, such as the manufacturing of complex near-net-shape geometries. In addition, AM offers the potential of manufacturing according to

Recommended for publication by Commission I - Additive Manufacturing, Surfacing, and Thermal Cutting

This article is part of the collection on Additive Manufacturing Processes, Simulation and Inspection

Thomas Hassel

hassel@iw.uni-hannover.de

1 Institut für Werkstoffkunde, Leibniz Universität Hannover (LUH), Hannover, Germany customer requirements, realizing lot size 1 , and regeneration of worn or defective components. In terms of resource conservation, the use of AM's repair potential is increasingly moving into the focus of research. According to EN ISO/ ASTM 52900 [2], there are seven groups of additive manufacturing processes. Metals can be printed with all groups, but processes from mainly two groups are used: directed energy deposition (DED) and powder bed fusion (PBF) [3]. Well-known processes for PBF are selective laser melting (SLM) and selective laser sintering (SLS). Processes of the group DED are laser metal deposition (LMD) and wire and arc additive manufacturing (WAAM). WAAM is the generic term for gas tungsten arc welding (GTAW), gas metal arc welding (GMAW) and plasma arc welding (PAW).

Robot-based WAAM is a promising manufacturing process that is still underrepresented. It combines the advantages of the significantly cheaper investment in equipment compared with all other systems with the less expensive consumable wire. By using wire instead of powder, there are, in 
addition to the variety of materials, advantages of lower pricing, lower health hazards and simplified storage. Furthermore, WAAM offers the potential to apply material to free-form surfaces in the form of repairs or extensions. The workspace is directly increased by extending the lead machine. The high application rate is only opposed by the minimum layer width of four millimetres. Due to the very high material variety, the mechanical properties are not yet determined for all available materials for WAAM. Especially in the field of AM of nickelbased alloys, only a few alloys have been investigated so far.

The mechanical properties of alloy 718 have been extensively investigated using SLM [4-8] and electron beam powder bead fusion [9-12]. Baufeld tested the mechanical properties of GTAW manufactured alloy 718 and compared them to other AM processes. He found that the tensile strength level of GTAW is slightly higher than as-cast but lower than AM applications with laser or electron beam [13]. Xu et al. compared the material properties of alloy 718 samples in as-build condition to heat-treated condition. For this purpose, they produced single-track walls using the GMAW process. In asbuild condition, the mechanical properties of the GMAW process are comparable to GTAW presented in [14]. The strength of the heat-treated samples was $105 \mathrm{MPa}$ lower than of the forged samples. Furthermore, they compared two wires of different suppliers and found a difference in tensile strength of around $50 \mathrm{MPa}$, most likely due to the difference in elemental composition [14]. Wu et al. analysed the resulting residual stresses as a function of different path planning strategies for GTAW. They printed alloy 718 in a rectangular shape with three deposition patterns: long, short and spiral. The use of short track lengths reduces the residual stress [15]. Chelbus et al. researched the mechanical properties of alloy 718 processed by SLM in as-build and heat-treated condition. They printed cubes and tested the properties in four directions (Y, Y-Z, Z and $\mathrm{X}-\mathrm{Y}-\mathrm{Z}$ ). $\mathrm{Y}$ is the scan/deposition direction, $Z$ is the build direction, $Y-Z$ is the diagonal of the $Y$ $Z$ plane, and $X-Y-Z$ is the diagonal of the $X-Y-Z$ space. They found that the tensile strength in $X-Y-Z$ direction is significantly higher in as-build than in the other three directions tested. After the heat treatment, the difference was smaller but measurable [8].

Jurić et al. studied the influence of shielding gas composition on the mechanical properties of alloy 625 using GMAW. They found that using a shielding gas with $2.5 \%$ carbon dioxide in argon would increase the tensile strength by $7 \%$ compared with pure argon, 5\% hydrogen in argon and 3\% helium $+1.5 \%$ hydrogen in argon [16]. Wang et al. used GTAW to manufacture walls of alloy 625 and tested the mechanical properties in deposition $(\mathrm{Y})$ and $\mathrm{BD}(\mathrm{Z})$. Ultimate tensile strength in deposition direction was slightly higher than in BD (Z), $722 \pm 17 \mathrm{MPa}$ compared with $684 \pm 23 \mathrm{MPa}$ [17]. Ma et al. investigated the crystallographic texture of additive manufactured alloy 625 . The samples were produces by
LMD. They found that the orientation $<100>$ is predominant and the grains are aligned at $45^{\circ}(\mathrm{Y}-\mathrm{Z})$ to $\mathrm{BD}$ [18]. Yadroitsev et al. studied the anisotropy of the mechanical properties in alloy 625. They build a cylinder using SLM and prepared vertical and horizontal samples. They chose samples in $0^{\circ}$ $(\mathrm{Y}), 45^{\circ}(\mathrm{X}-\mathrm{Y}), 90^{\circ}(\mathrm{Y})$ and $\mathrm{BD}(\mathrm{Z})$. No essential differences of the mechanical properties were found [19].

To the knowledge of the authors, no research regarding the mechanical properties of additive manufactured alloy 617 has been published. Alloy 617 (UNS N06617) is a nickel-based alloy consisting of the main components nickel, chromium, cobalt and molybdenum. Due to its good corrosion properties, good strength and oxidation resistance at high temperatures, the alloy is widely applied for high-temperature components like gas turbines, high-temperature heat exchangers and air heaters. Alloy 617 is a candidate for being approved by ASME Section III Subsection NH. As a result, it would be used for the reactor internals and intermediate heat exchangers of helium-cooled very high-temperature reactors (VHTR) [20].

This paper closes the gap of the missing research for the properties of additive manufactured alloy 617 . The literature shows that the additive manufacturing processes cause anisometric properties due to the directed energy input. However, these are rarely investigated as samples are only taken in the deposition $(\mathrm{Y})$ and build direction $(\mathrm{Z})$. In this paper, samples in the interesting Y-Z direction are also taken and discussed.

\section{Material and methods}

\subsection{Setup and material}

All samples were prepared using the test rig shown in Fig. 1. The lead system consists of two KUKA six-axis industrial robots. The welding torch is attached to the KUKA KR16-2. This allows complete freedom in setting the welding torch angle. The substrate plate is mounted on the KUKA KR125. This allows all welding positions PA to PE to be tested. The welding system used was the power source model Phoenix 521 coldArc from EWM with the welding torch model AUT 501 from Abicor Binzel.

Starting with a CAD file of the part that is to be printed, the model is broken down into layers, and the path planning is carried out for each layer. The resulting robot program is executed with the robots. In the case of the printed walls, the path planning is shown in Fig. 2.

The substrate was cut from flat material of the material S235JR to the dimensions $370 \times 100 \times 10 \mathrm{~mm}$ and afterwards cleaned with ethanol. The wire used was alloy 617 (Sanicro 53) with a diameter of $1.0 \mathrm{~mm}$ from Sandvik AB. The chemical composition of the wire is shown in Table 1. 
Fig. 1 (Left) Robot-based welding setup at Institute of Materials Science of LU Hanover; (right) welding process of vertically walls made from alloy 617 . The welding torch is attached to the KUKA KR-16 (left no. 2). The substrate is mounted on the KUKA KR-125 (left no. 3). The welding machine in the background (left no. 1)

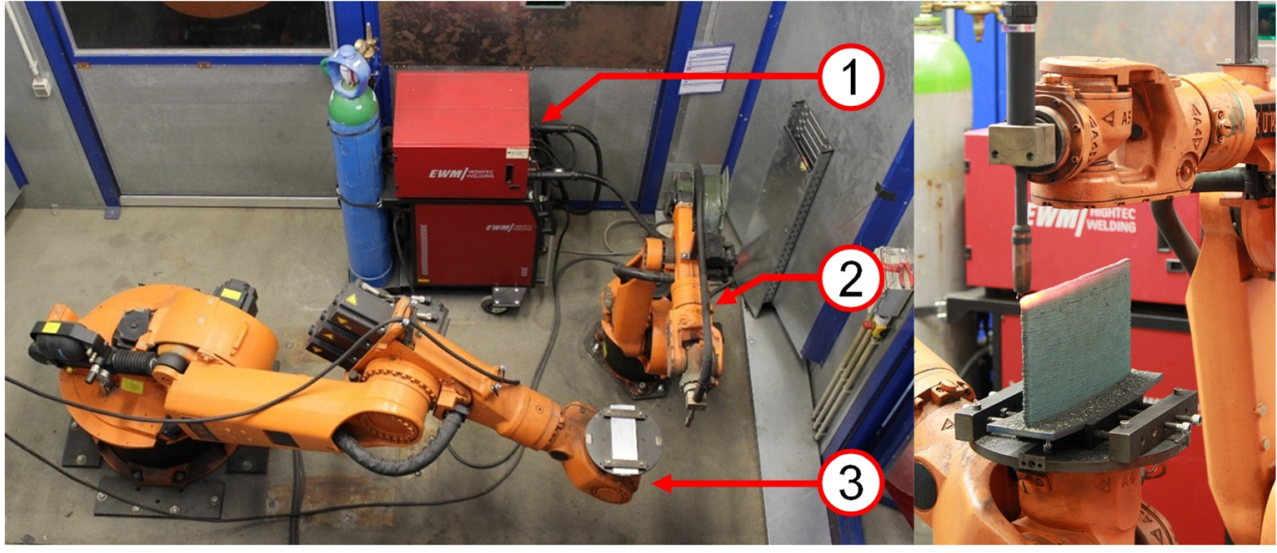

For the studies, three walls with the dimensions $7 \times 350 \times$ $210 \mathrm{~mm}$ have been produced. As welding job, the coldArcJob 67 supplied by EWM was selected. ColdArc is a variant of the GMAW with reduced heat input. The shielding gas was argon with $20 \%$ helium and $2 \%$ carbon dioxide with a flow rate of 12 1/min. Deposition parameters are shown in Table 2. After welding, the nickel oxide layer was removed using the pickling agent Formula Green in combination with a neutralization solution from Sandvik AB.

\subsection{Analytical methods}

The samples were cut from the walls using water jet cutting. For each of the three walls and each of the three directions (Y, $\mathrm{Y}-\mathrm{Z}, \mathrm{Z})$, five tensile specimens were taken. Additionally, two micro-tensile specimens each in (Y), (Y-Z) and (Z) direction were taken for examinations in the scanning electron microscope, as well as six samples for metallographic examination. The position of the samples can be seen in Fig. 3 .

The light microscopy samples were embedded, ground, polished and etched with Adler's reagent.The images were taken with a microscope camera of the type DP72 by Olympus.

The tensile specimens and micro-tensile specimens were machined to the dimensions according to DIN EN 50125 shown in Fig. 4. Both sides of the micro-tensile specimens were polished, and one side etched with $3 \mathrm{ml}$ hydrofluoric acid in $80 \mathrm{ml}$ nitric acid. The images were taken with a

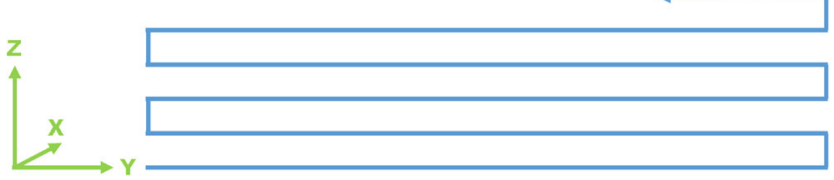

Fig. 2 Path planning for weld. The welding direction alternates with each layer. The first layer is welded in $-Y$ direction. The welding process is stopped at the end of each layer. After a cooling phase of $30 \mathrm{~s}$, the welding torch is moved by the layer height in the $\mathrm{Z}$ direction. The second layer is welded in the $+Y$ direction opposite of the first layer. The welding direction changes with every layer microscope camera of the type DP72 by Olympus. One side of the tensile specimens was polished, and a ZHU 250 universal testing machine from Zwick was used to measure Vickers hardness $\left(\mathrm{HV}_{10}\right)$ according to DIN EN ISO 6507-1. All samples were fixed in the ZHU 250 identically. A load of $98.07 \mathrm{~N}$ was applied for $13 \mathrm{~s}$ on three points in the shaft of each specimen. The tensile test was carried out according to DIN EN ISO 6892:2016 on the Zwick Z250 universal testing machine. The extensometer length was $20 \mathrm{~mm}$ and the test speed $0.06 \mathrm{~mm} / \mathrm{s}$ to $R_{\mathrm{p} 0.2}$ from then on $0.15 \mathrm{~mm} / \mathrm{s}$.

The deformation behaviour under tensile load was investigated on polished micro-tensile specimens in a scanning electron microscope in high vacuum. The examination of the tensile test was performed with the high-resolution field emission scanning electron microscope (SEM) SUPRA 55VP from Zeiss using a secondary electron detector in combination with a tensile module with DDS control from Kammrath \& Weiss. The X-ray powder diffraction (XRD) measurements were performed with a Bruker D8 Discover with cobalt anode.

\section{Results and discussion}

\subsection{Metallography}

In contrast to the casting process, the layer-by-layer building process of AM parts represents a strongly anisotropic process. The continuously moving local heat source and the melt pool are moved in deposition direction $(\mathrm{Y})$ and in $\mathrm{BD}(\mathrm{Z})$. This results in an almost directional solidification in relation to the BD. The linear design of the additive process is not only reflected by the wavy surface structure but has also effects on the microstructure and on the resulting properties of the material. This circumstance, which is used by targeted solidification processes in the area of Ni-based alloys because of the advantageous property formation, also arises during welding due to the directional process control of the heat input. Figure 5 shows this in an impressive way, since grain sizes of more than $10 \mathrm{~mm}$ can be detected in cross section although 
Table 1 Chemical composition (\%wt) of the filler wire

\begin{tabular}{lllllllll}
\hline Elements in weight $\%$ & $\mathrm{Ni}$ & $\mathrm{Cr}$ & $\mathrm{Mo}$ & $\mathrm{Co}$ & $\mathrm{Fe}$ & $\mathrm{Si}$ & $\mathrm{C}$ & $\mathrm{Mn}$ \\
\hline Filler wire (Alloy 617) & Balance & 22.50 & 9.00 & 11.50 & 0.50 & 0.20 & 0.06 & 0.04 \\
\hline
\end{tabular}

the layer height is only $1.6 \mathrm{~mm}$. Sun et al. described this effect deeply in the case of powder-based electron beam additive manufacturing of alloy 718 . They investigated the properties of the material for varying build directions and concluded that the crystallographic orientation in the as-build conditions is the base of the strengthening of the material. Due to the columnar grain growth during the manufacturing process, a highly anisotropic metallographic structure is created. However, the crystallographic orientation of the stem crystals is dominant in $<001>$ direction and shows a crystallographic texture for this cubic face-centred material. Furthermore, the influencing parameters due to macroscopic errors such as porosity, the direction-dependent arrangement of precipitates and grain boundaries are considered, which, however, have no influence on the expected anisotropy behaviour. However, the temperature-dependent property profile is influenced by the phase formation of the precipitates caused by heat treatment [21].

Under WAAM conditions, the remelting of an already solidified grain leads to a crystallographic orientation of the material. This can clearly be seen in Fig. 5 from the continuous microstructure, although a heat-affected zone is visible across it. Disturbances of the process show a new grain formation by the fusion of fine-grained solidified material to coarse grain areas, which grow several millimetres in one direction (Fig. 5). To check whether the grains continue to grow over the layers, diffraction images were taken with an $\mathrm{XRD}$ at the points marked in Fig. 6 on the left. In the diffraction images (see Fig. 6 on the right), only single reflections are

Table 2 Deposition parameters

\begin{tabular}{ll}
\hline Gas & $\mathrm{Ar} / 2 \% \mathrm{CO}_{2} / 20 \% \mathrm{He}$ \\
\hline Gas flow rate & $12 \mathrm{l} / \mathrm{min}$ \\
Wire & Sanicro 53 , alloy 617 \\
Wire diameter & $1.0 \mathrm{~mm}$ \\
Wire feed & $5.4 \mathrm{~m} / \mathrm{min}$ \\
Welding Job & EWM coldArc \\
Current & $90 \mathrm{~A}$ \\
Voltage & $20.4 \mathrm{~V}$ \\
Travel speed & $0.45 \mathrm{~m} / \mathrm{min}$ \\
Layer height & $1,6 \mathrm{~mm}$ \\
Contact tip-to-work distance & $15 \mathrm{~mm}$ \\
Torch angle & $0^{\circ}$ \\
Dwell time between layers & $30 \mathrm{~s}$ \\
\hline
\end{tabular}

visible, as it is usual for single crystals, large grains or texture. The diffraction patterns are nearly identical, which means it is the same grain grown over several layers or two grains with nearly identical orientation. The explanation for this is the inhomogeneous heat dissipation caused by the migrating arc, whereby crystallization is characterized by increased nucleation and low nucleus growth. At the interface of solid to liquid of the already existing seam, heterogeneous nucleation begins in the super cooled melt due to the high heat gradient. The existing weld seam can also provide foreign nuclei if the surface is wetted by the melt. Nuclei in the melt near the solidification temperature form grains. The nuclei above a minimum size are capable of growth. Around the growing nuclei, atoms arrange themselves to a crystal lattice. The crystallite begins to grow. The kinetic energy of the atoms from the melt is suddenly reduced by the attachment to a crystal lattice, since there are only small movements possible. This energy difference is released as heat of crystallization and must constantly be emitted. The nuclei grow in an undirected form, with heat flow in all directions. The elongated grain visible in the microstructure is formed as a stem grain due to the low subcooling caused by the low heat gradient. The solidification front, which moves into the melt, is directed against the heat flow. Grain growth occurs almost exclusively because the subcooling is not sufficient to form new nuclei [20]. The fact that fine grains and stem grains are present is due to the different heat dissipation in the component and seam. Thus, the heat gradient and the subcooling of the melt are decisive for whether nucleation with or without growth preferably occurs. Is the heat dissipation homogeneous, the nucleation rate decreases, and nucleation growth dominates the solidification process. This means that a directionally solidified grain in the component can continue to grow during the application of the next layer and thus large crystals can be produced in the WAAM process. This texture in the grain structure can have a major influence on the anisotropic properties of the material, provided that the crystalline orientation is textured as well. If the intermediate temperature is too low, the subcooling of the following weld bead is too large and fine grain formation occurs at the solidification line. As the temperature gradients decrease, this results in a large grain again (see Fig. 5 on the right). Visionary the WAAM process allows the mapping of property profiles comparable to the technical single crystal.

The metallographic investigations show a low-porosity weld with precipitations along the grain boundaries and micropores up to a size of less than $10 \mu \mathrm{m}$, which can be seen in 
Fig. 3 Cutting plan for all three walls. Five tensile samples (white) for each direction. Two micro-tensile samples (blue) for each direction. Six samples for microscopic analyses (green). Y is in deposition direction, and $\mathrm{Z}$ is in build direction (BD)

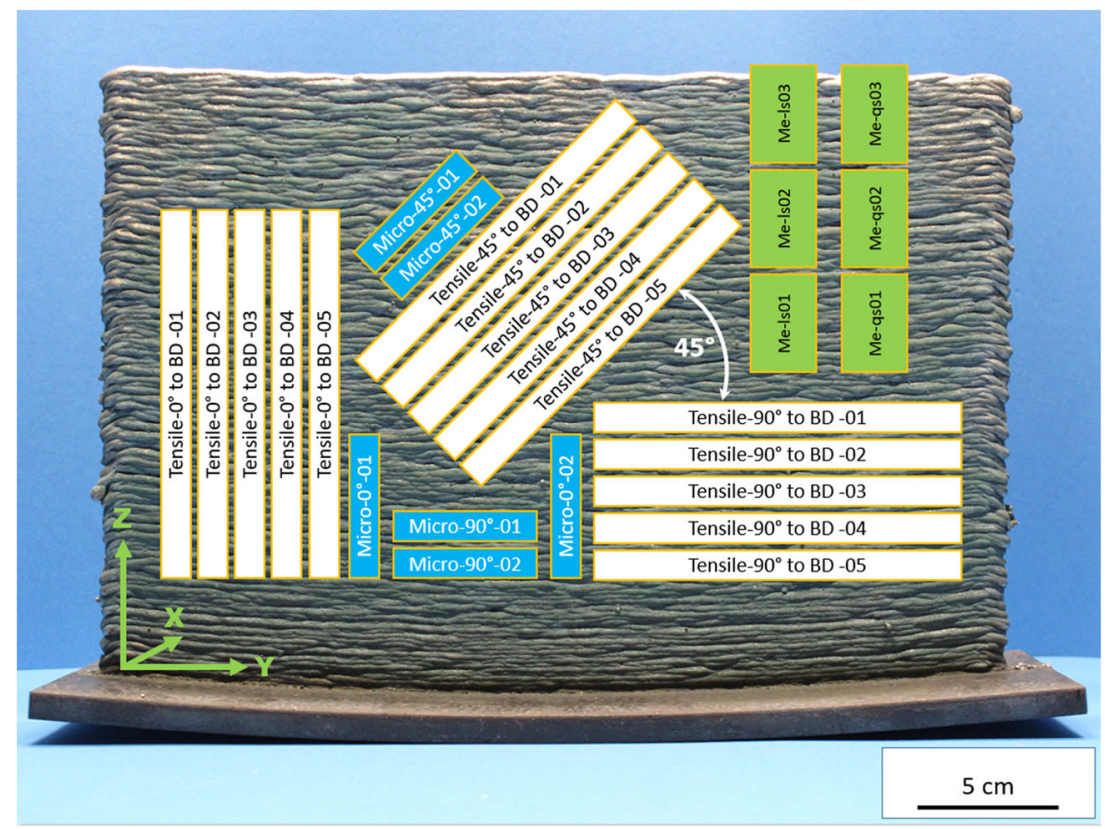

the SEM microsections in the form of round, black areas (Fig. 7). This has also been reported by Wang et al. [17]. The micropores are forming lines along the BD. Large pores or pore nests, which are often typical for gas-shielded welding processes, do not occur in this production and the selected material system.

\subsection{Strength behaviour at room temperature}

The highly textured structure caused by the directional grain growth shows an anisotropic strength behaviour at room temperature. The $\mathrm{BD}$ determines the mechanical properties in the plastic deformation range which, however, cannot be explained by the grain structure alone. As Fig. 8 shows, different mechanical properties are achieved in the as-welded state in various directions with respect to the BD. Despite the scatter bands measured within the sample size of $3 \times 5$ specimens, it is noticeable that in the test direction $45^{\circ}$ to $\mathrm{BD}(\mathrm{Y}-\mathrm{Z})$, an increased tensile strength with increased yield strength and simultaneous reduction of elongation is recorded. In deposition direction $(\mathrm{Y})$ and in $\mathrm{BD}(\mathrm{Z})$, the material shows a lower strength and an increased plastic deformability. Quantitatively, the change to the test direction of $45^{\circ}$ (Y-Z) results in an increase of the tensile strength by approximately 25-45 MPa. In the area of the yield strength, there is an increase of approximately $30 \mathrm{MPa}$, and the fracture strain is reduced by about $1-4 \%$. Due to the scattering of the measured values, this result is not unambiguous and can only be interpreted as a trend statement. While the anisotropy effects in the high-temperature range are assigned to the ' $\gamma$ ' phase

Fig. 4 Geometry of tensile and micro-tensile specimens

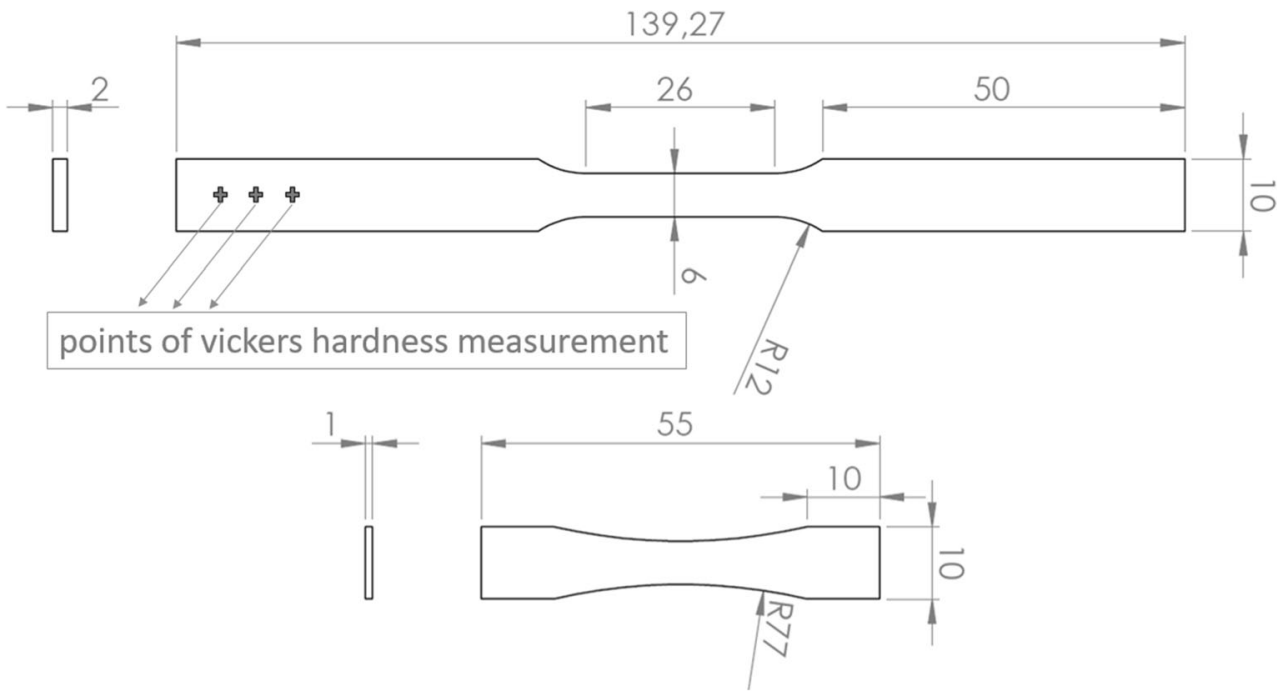


Fig. 5 Cross sections etched with Adler's reagent represent the precipitation structure and the porosity

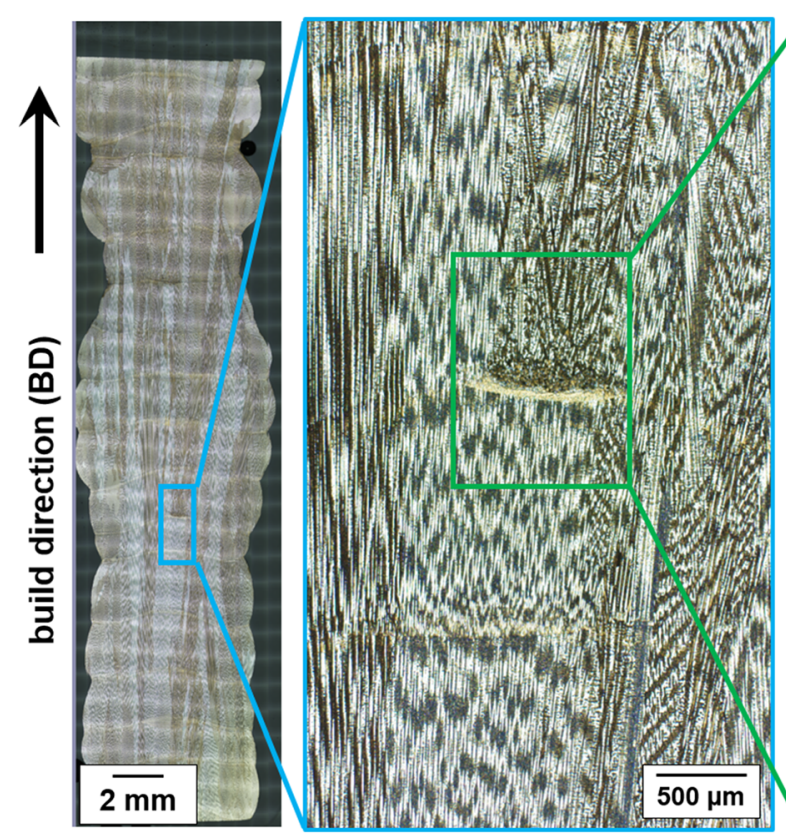

formation, the reasons of the room temperature range of the present material are rather crystallographically based anisotropy. The knowledge in the literature on both elastic and plastic deformation shows the typical properties of a cubic crystal. For example, the directional dependence of the modulus of elasticity [22, 23] and the orientation-dependent formation of the strength properties at room temperature $[24,25]$ can be mentioned here.

In order to understand why the anisotropy occurs and how it can be explained, micro-tensile tests were performed in the SEM. The behaviour of tensile specimens in the plastic deformation range on polished surfaces was studied as a function of direction. It is known that the cubic space-centred Ni-based alloys deform according to an octahedron sliding due to the sliding of densely packed atomic planes. The sliding process on the surface results in typical steps which are clearly visible. The number, the alignment to each other and the behaviour at disturbances, e.g. grain boundaries or precipitates, can also be studied. Simple or double sliding systems can be identified, and the crystallographic oriented sliding direction can be inferred from the angular arrangement of the sliding stages. The inclination of the tensile axis in relation to the position of the crystallographic planes is of interest, since by considering Schmid's shear stress law (Eq. (1)), the shear stress required to activate the respective sliding planes can be calculated. This consideration makes an interpretation of anisotropic property profiles
Fig. 6 Analysis of grain growth. On the left, the two measuring points are marked in red. On the right, XRD diffraction patterns measured with a $0.3 \mathrm{~mm}$ measuring area. The upper diffraction image is from the upper measuring point. The lower diffraction image is from the lower measuring point
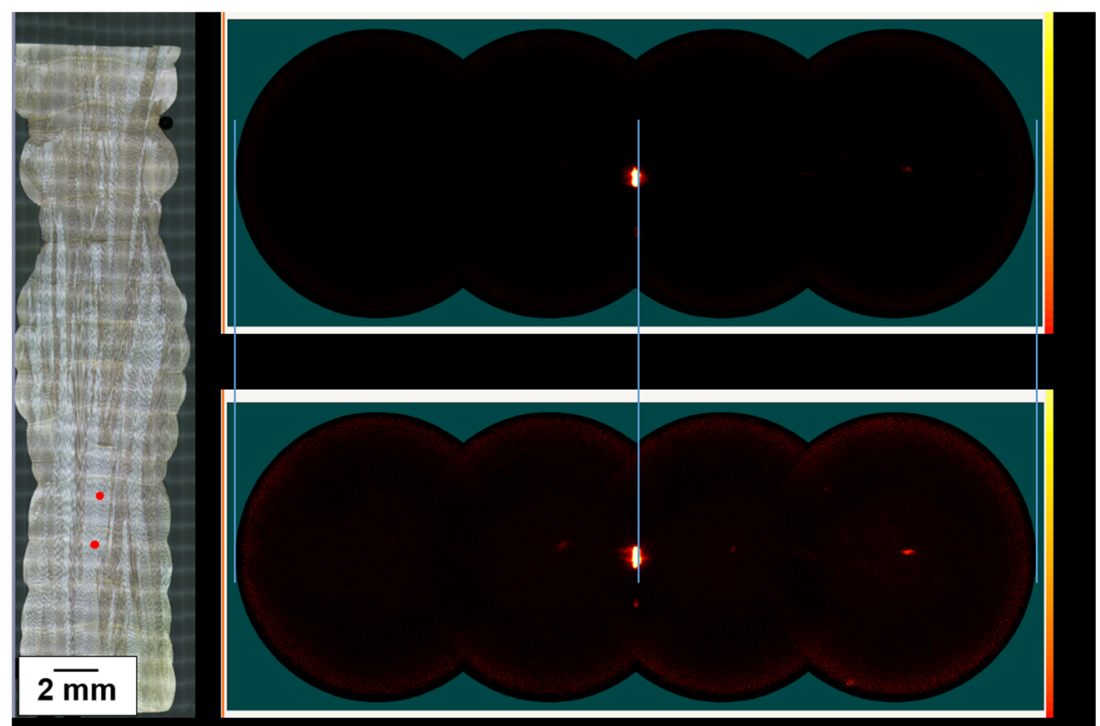


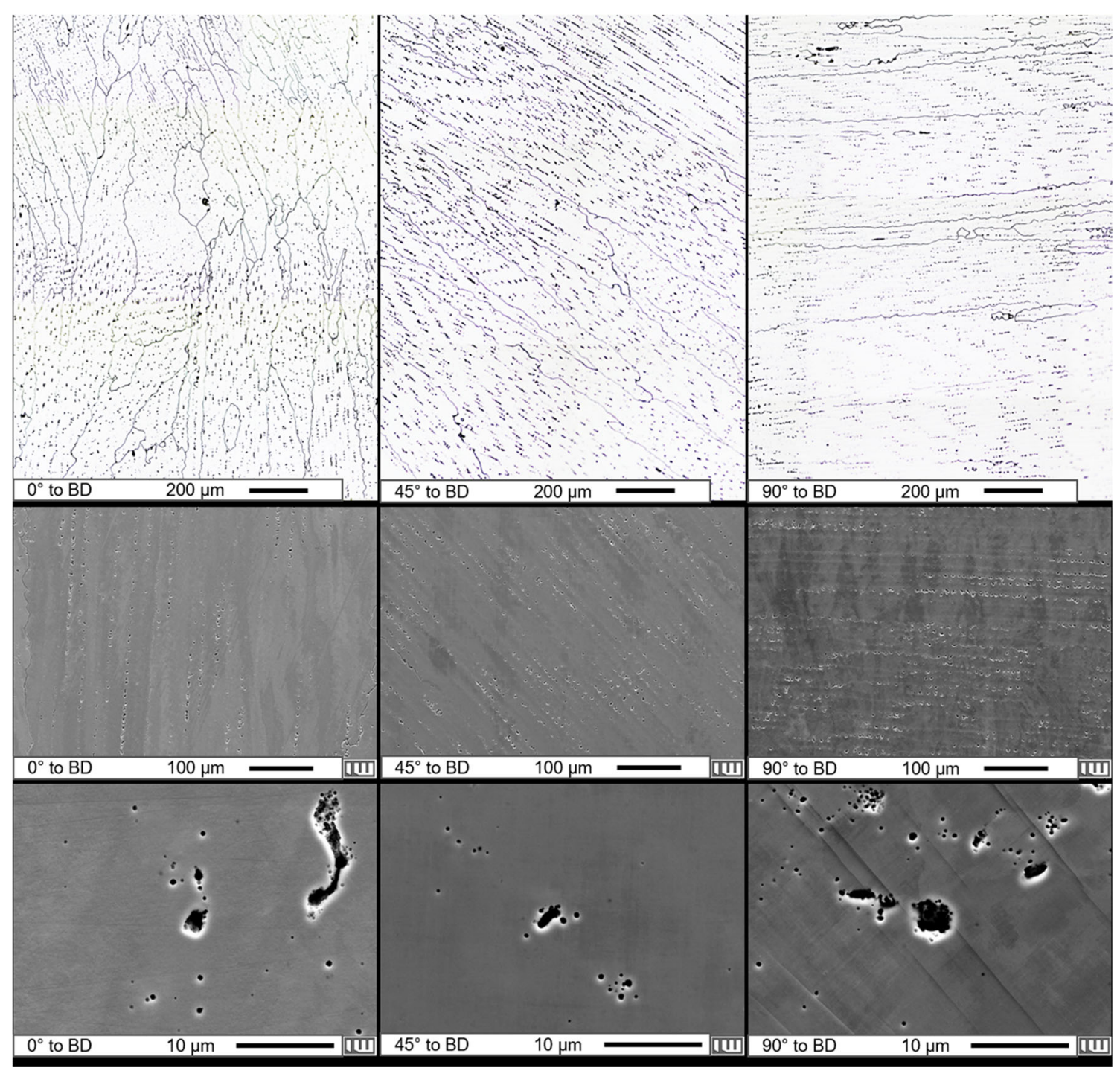

Fig. 7 Precipitation and porosity in the WAAM material. (Top) Microscopic images etched with $3 \mathrm{ml}$ hydrofluoric acid in $80 \mathrm{ml}$ nitric acid. (Bottom) SEM with secondary electron detector

Fig. 8 Strength behaviour of the WAAM structure $0^{\circ}, 45^{\circ}$ and $90^{\circ}$ in relation to the building direction of the material

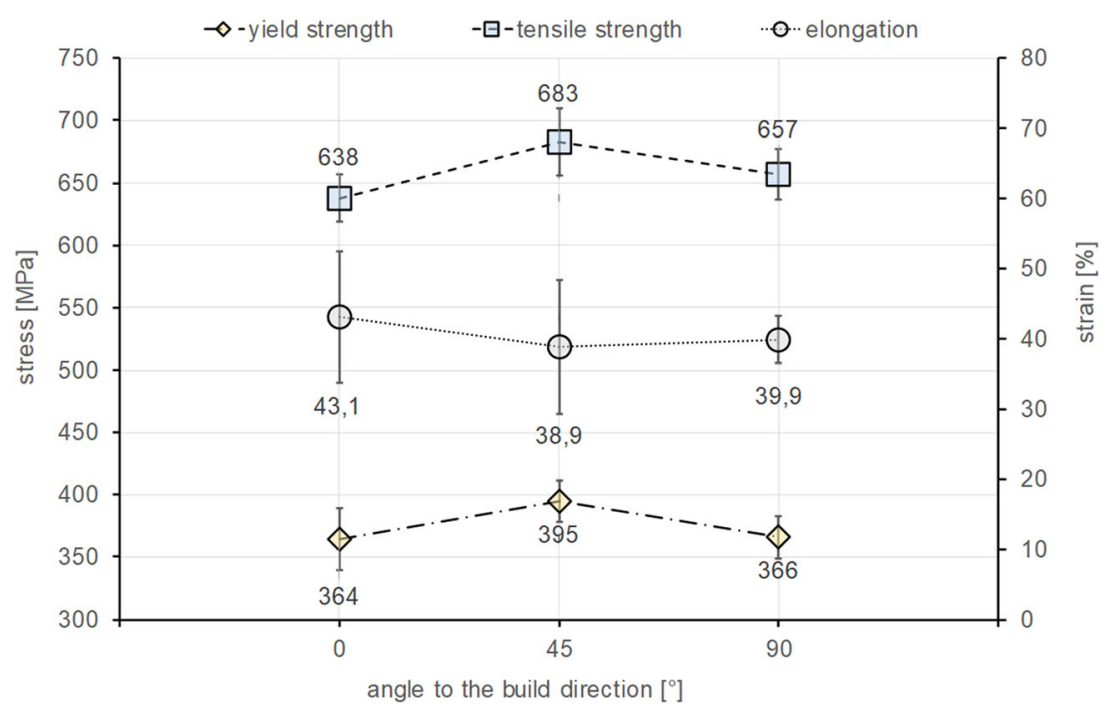


Fig. 9 Dependencies of the angular relationships under application of Schmid's shear stress law for the case of a double conduction in bfc-material

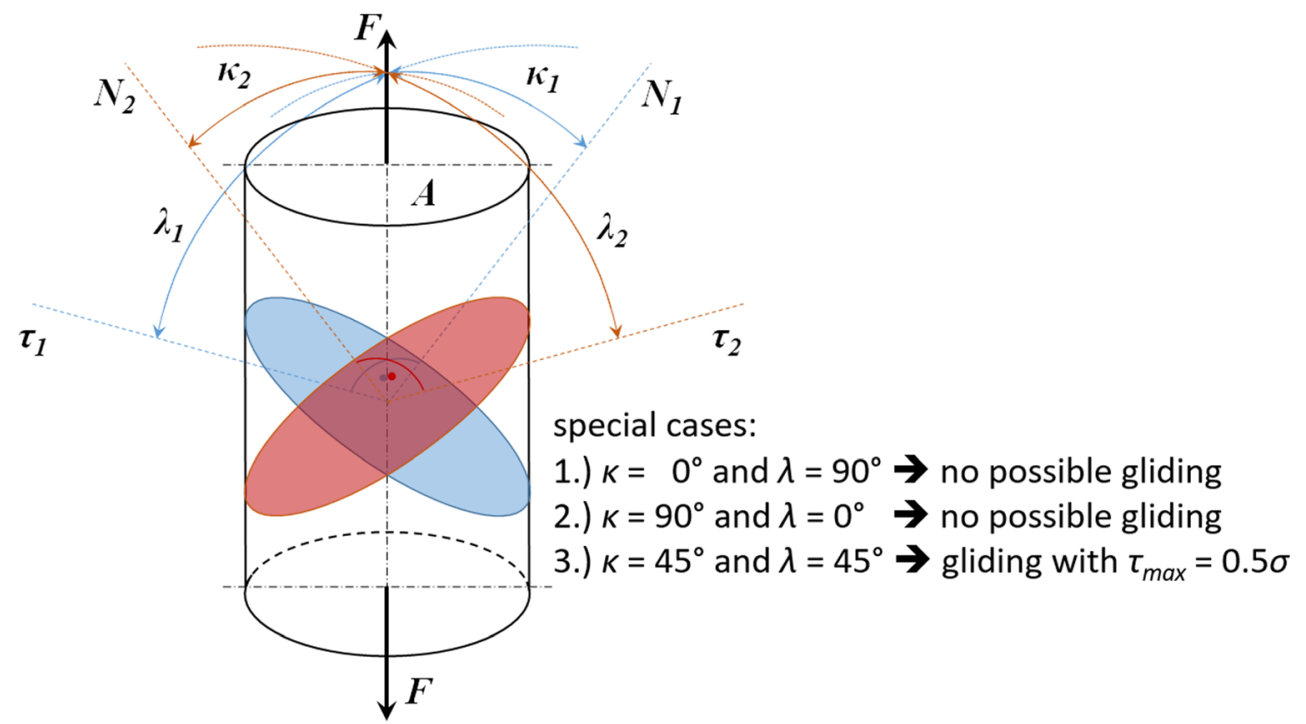

possible, provided that the processes of deformation by sliding of crystal planes are known for the material.

$\tau=\sigma \cdot \cos \kappa \cdot \cos \lambda=S \sigma$

where $S$ is the Schmid factor, $\kappa$ the angle between tensile direction and slip plane standards, $\lambda$ the angle between tensile direction and slip direction, $\tau$ the resulting shear stress and $\sigma$ the tensile stress.

In case of the investigated Ni-based alloy, a clear directiondependent formation of the sliding plane systems can be seen. In the tensile tests of $0^{\circ}$ and $90^{\circ}$ to the $\mathrm{BD}$, double sliding systems are formed which can clearly be seen in Fig. 11 in form of angularly offset sliding stages. The activation of this double sliding system shows that the activation energy $\tau$ for the displacement of sliding systems in different directions is reached by the applied tensile stress. Therefore, under consideration of the angular relationship in Schmid's law, there are areas in which both $\kappa$ and $\lambda$ are similar in size and therefore result in similar shear stresses as activation for the sliding process, as Fig. 9 shows. In the stress-strain diagram (Fig. 10), this is shown by a low yield strength. The shear stress for sliding of the atomic planes is very high; therefore, the plastic deformation begins at low tensile stresses. It also shows that the hardening, i.e. the dislocation formation in the range from $0^{\circ}$ to $\mathrm{BD}$, above the plastic deformation is higher than at $90^{\circ}$ to BD. In Fig. 11, this is illustrated by the higher
Fig. 10 Stress-strain diagram of the micro-tensile tests correlated with SEM observation to present the anisotropic gliding operations

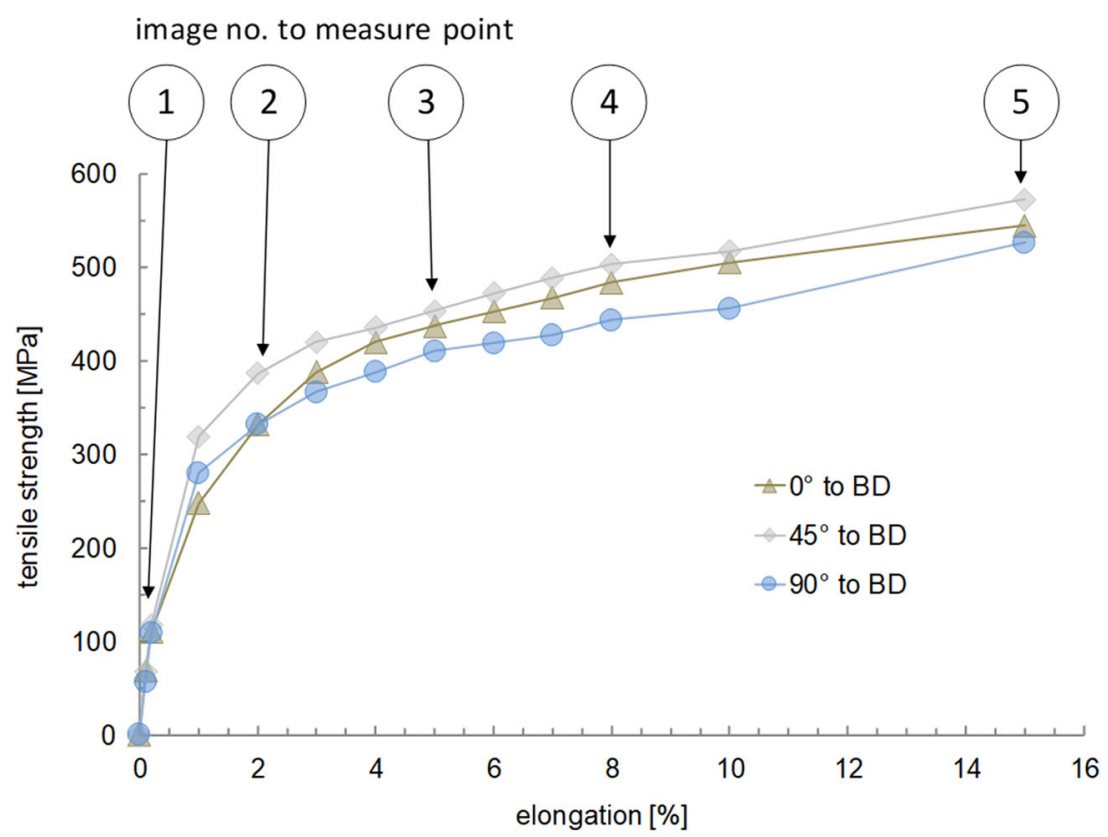


Fig. 11 SEM observation of the surface deformation during micro-tensile test results correlated with SEM observation to present the anisotropic gliding operations in different load directions to the built direction (BD)

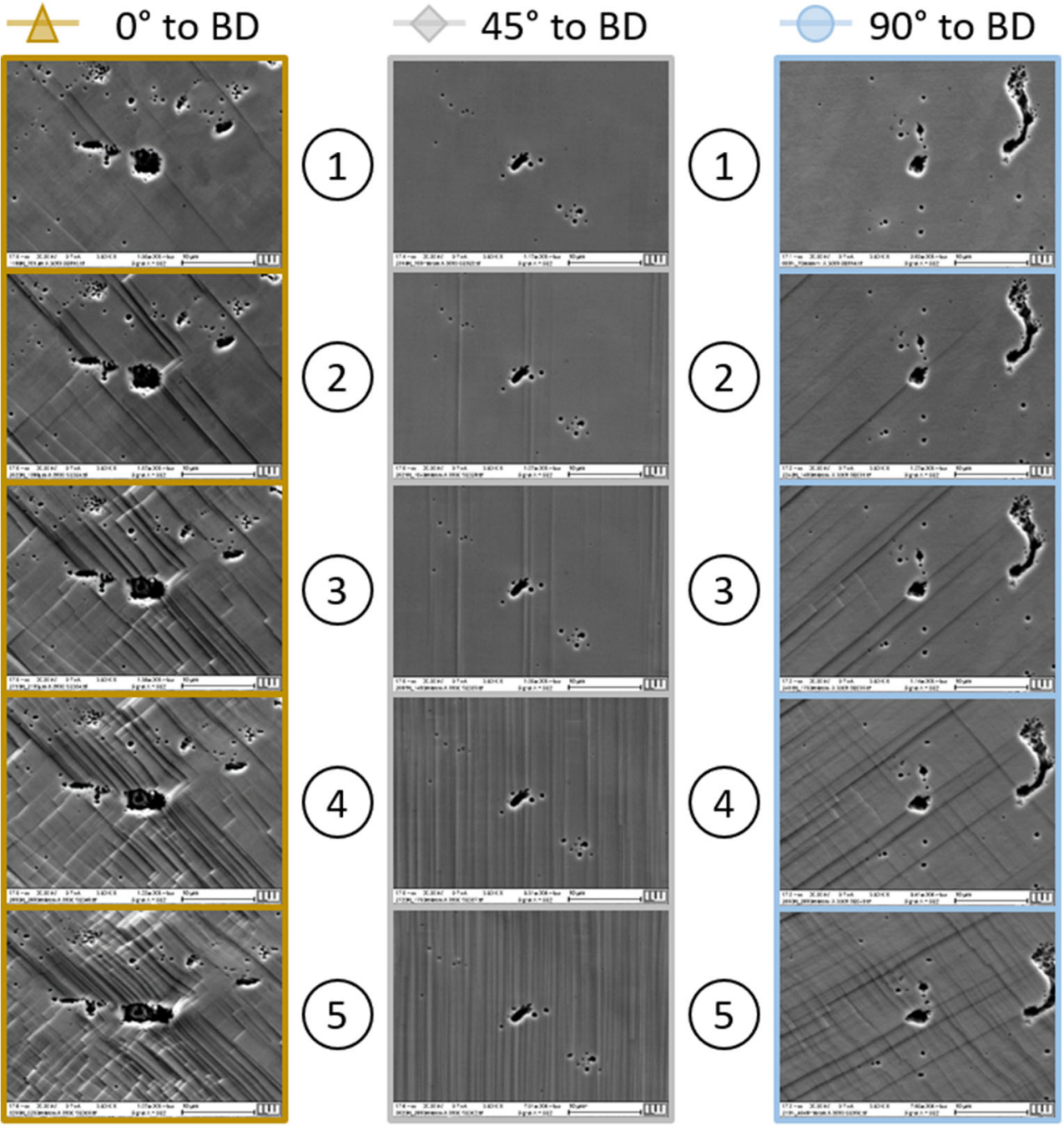

$10 \mu \mathrm{m}$ (scale for all pictures) number of sliding steps, which can be interpreted as a measure of dislocation density.

The deformation processes at $45^{\circ}$ to $\mathrm{BD}$ are completely different, as only one sliding system has been activated. This means that the double sliding system is not activated in this test direction. Only one sliding system is available for plastic deformation. Since the entire deformation must manifest itself through the dislocation formation and the sliding of atomic planes when the yield point is exceeded, the dislocation formation is only present in one of the sliding systems. For the same plastic deformation, a considerably higher number of dislocation movements are expected in the activated sliding system, and this results in solidification. This can be seen in the stress-strain diagram of the micro-tensile test in form of the higher yield strength and the increased strength behaviour compared with the other two tensile test directions in $0^{\circ}$ and $90^{\circ}$ to BD (Figs. 10 and 11).
At first sight, the hardness measurements shown in Fig. 12 appear to contrast with the strength and strain behaviour. In $\mathrm{BD}$ and $90^{\circ}$ to $\mathrm{BD}$, the hardness is higher than in $45^{\circ}$ to $\mathrm{BD}$. Although the measured values are within the scatter bands, a systematic dependency can easily be identified as a trend. The anisotropic behaviour, especially the lower hardness with higher strength for the $45^{\circ}$ direction (Y-Z), can be explained by the discussion of the test method. Since the hardness was measured at the flat ends of the tensile specimens and the specimens were always positioned identically on the test table, the direction of the pyramidal surfaces of the Vickers pyramid is dependent on the $\mathrm{BD}$ (Fig. 12). If the test specimen now penetrates the material, shear stresses in the normal direction are induced on its surfaces. Thus, the system activates shear stresses in four directions in the material, which leads to the activation of sliding systems and thus to plastic deformation through material displacement. In $\mathrm{BD}$ and $90^{\circ}$ to it, this shear stress acts in a direction in which fewer slip planes can be 
Fig. 12 Vickers hardness in dependence to the build direction

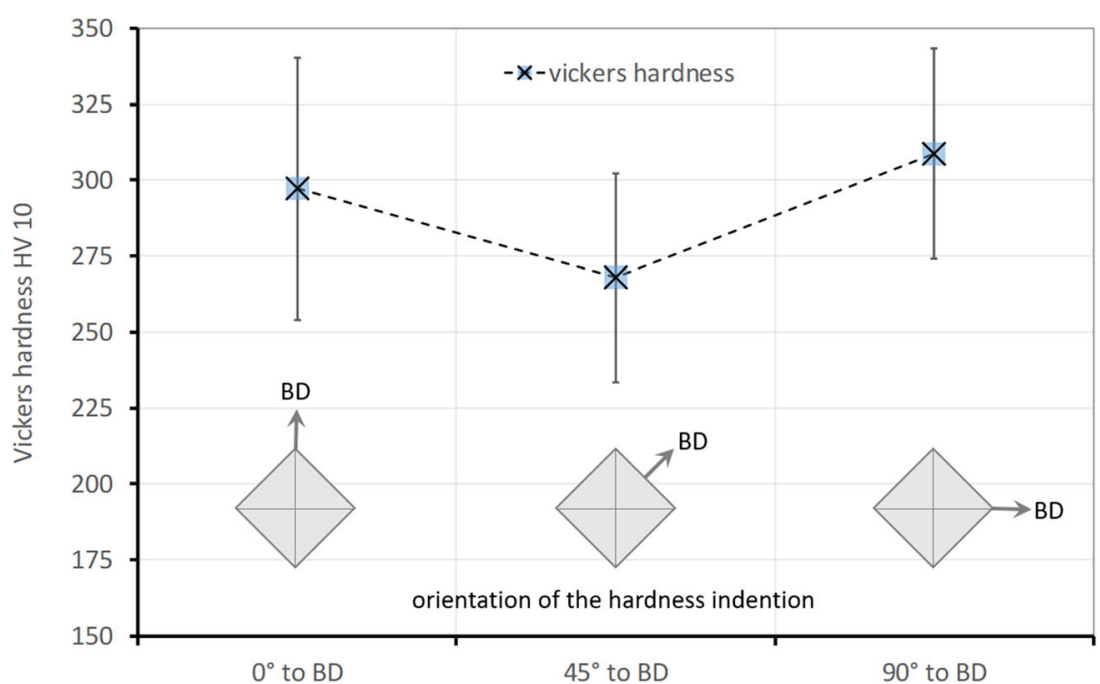

activated, whereby the dislocation density increases and strengthening takes place. This can be seen in the increased hardness in $\mathrm{BD}$ and $90^{\circ}$ to $\mathrm{BD}$. In case of $45^{\circ}$ to $\mathrm{BD}$, more sliding systems are activated by application of force of at the pyramid surfaces, so that a larger plastic deformation is detected. This corresponds to a greater material displacement, which results in a reduced hardness. This shows that there is a crystallographic preferred orientation in the material, which makes the deformation behaviour anisotropic, but hardly plays a dominant role in its quantity at room temperature.

\section{Conclusion}

In summary, it can be said that the GMAW-based WAAM process in combination with robotics is a cost-effective and extremely versatile alternative to many other additive manufacturing processes. The positioning accuracy is absolutely sufficient to produce three-dimensional structures with the GMAW process, and there are manifold possibilities for the complete automation of this process technology.

In addition to many other materials available in wire shape, nickel-based alloys in particular can be processed. Using the example of alloy 617 , it was shown that distortion-free singletrack structures in the form of walls measuring $350 \times 210 \mathrm{~mm}$ can be produced by layer-by-layer welding.

The mechanical properties and the hardness show an anisotropy related to the $\mathrm{BD}$, which tends to be recognizable, although the scattering of the measured values does not permit this statement unambiguously due to a certain overlap. There is an increase in strength in the direction of $45^{\circ}$ to $\mathrm{BD}$ with a simultaneous reduction in elongation. In $\mathrm{BD}$ and $90^{\circ}$ to $\mathrm{BD}$, the mechanical properties are at a comparable level. By interpreting the slip lines of micro-tensile tests in the SEM, statements can be made about the anisotropic behaviour under deformation. While double sliding systems are activated at
$\mathrm{BD}$ and $90^{\circ}$ to $\mathrm{BD}$, only one sliding system is activated at $45^{\circ}$ to BD. With different patterns of the slip lines, it can be assumed that a dominant crystallographic direction exists. A targeted control of the solidification front can make the processing of nickel-based alloys by WAAM direction dependent. So that elongation and strength reserves can be utilized in certain directions, provided that the component coordinate systems can be adapted to the crystal growth directions.

This means WAAM could be used to generate components with directionally property profiles. Through the intelligent combination of the possibilities of robot-based motion systems and the WAAM process, the generation of directionoptimized properties can already be considered in the path planning. By optimizing the heat management, perspectives are created that enable the generation of components in the form of technically monocrystalline structures, such as those used in turbines. This also opens up realistic and economical possibilities for repairing and reconditioning such costintensive components by means of single-crystal repair, so that the product life cycle per component can be extended. In this way, the WAAM process can contribute to significant cost savings and overcome previous limitations through targeted process control.

Further investigations on the alignment of the grains and the control of the alignment will be carried out.

Acknowledgements Open Access funding provided by Projekt DEAL.

Open Access This article is licensed under a Creative Commons Attribution 4.0 International License, which permits use, sharing, adaptation, distribution and reproduction in any medium or format, as long as you give appropriate credit to the original author(s) and the source, provide a link to the Creative Commons licence, and indicate if changes were made. The images or other third party material in this article are included in the article's Creative Commons licence, unless indicated otherwise in a credit line to the material. If material is not included in the article's Creative Commons licence and your intended use is not permitted by 
statutory regulation or exceeds the permitted use, you will need to obtain permission directly from the copyright holder. To view a copy of this licence, visit http://creativecommons.org/licenses/by/4.0/.

\section{References}

1. Associates W (2019) Wohlers report 2019: 3D printing and additive manufacturing state of the industry. Wohlers Associates, Fort Collins

2. DIN Deutsches Institut für Normung e.V., Additive FertigungGrundlagen — Terminologie, 6th ed. 01.040.25; 25.030(52900), 2017

3. Oliveira JP, Santos TG, Miranda RM (2020) Revisiting fundamental welding concepts to improve additive manufacturing: from theory to practice. Prog Mater Sci 107:100590

4. Trosch T, Strößner J, Völkl R, Glatzel U (2016) Microstructure and mechanical properties of selective laser melted Inconel 718 compared to forging and casting. Mater Lett 164:428-431

5. Strößner J, Terock M, Glatzel U (2015) Mechanical and microstructural investigation of nickel-based superalloy IN718 manufactured by selective laser melting (SLM). Adv Eng Mater 17:1099-1105

6. Aydinöz ME, Brenne F, Schaper M, Schaak C, Tillmann W, Nellesen J, Niendorf T (2016) On the microstructural and mechanical properties of post-treated additively manufactured Inconel 718 superalloy under quasi-static and cyclic loading. Mater Sci Eng A 669:246-258

7. Amato KN, Gaytan SM, Murr LE, Martinez E, Shindo PW, Hernandez J, Collins S, Medina F (2012) Microstructures and mechanical behavior of Inconel 718 fabricated by selective laser melting. Acta Mater 60:2229-2239

8. Chlebus E, Gruber K, Kuźnicka B, Kurzac J, Kurzynowski T (2015) Effect of heat treatment on the microstructure and mechanical properties of Inconel 718 processed by selective laser melting. Mater Sci Eng A 639:647-655

9. Unocic K, Kolbus L, Dehoff R, Dryepondt S, Pint B (2014) Hightemperature performance of UNS N07718 processed by additive manufacturing

10. Sames WJ, Unocic KA, Dehoff RR, Lolla T, Babu SS (2014) Thermal effects on microstructural heterogeneity of Inconel 718 materials fabricated by electron beam melting. J Mater Res 29: 1920-1930

11. Kirka MM, Medina F, Dehoff R, Okello A (2017) Mechanical behavior of post-processed Inconel 718 manufactured through the electron beam melting process. Mater Sci Eng A 680:338-346

12. Deng D, Moverare J, Peng RL, Söderberg H (2017) Microstructure and anisotropic mechanical properties of EBM manufactured
Inconel 718 and effects of post heat treatments. Mater Sci Eng A 693:151-163

13. Baufeld B (2012) Mechanical properties of INCONEL 718 parts manufactured by shaped metal deposition, (SMD). J Mater Eng Perform 21:1416-1421

14. Xu X, Ding J, Ganguly S, Williams S (2019) Investigation of process factors affecting mechanical properties of INCONEL 718 superalloy in wire + arc additive manufacture process. J Mater Process Technol 265:201-209

15. Wu Q, Mukherjee T, Liu C, Lu J, DebRoy T (2019) Residual stresses and distortion in the patterned printing of titanium and nickel alloys. Additive Manufacturing 29:100808

16. Jurić I, Garašić I, Bušić M, Kožuh Z (2019) Influence of shielding gas composition on structure and mechanical properties of wire and arc additive manufactured Inconel 625. JOM 71:703-708

17. Wang JF, Sun QJ, Wang H, Liu JP, Feng JC (2016) Effect of location on microstructure and mechanical properties of additive layer manufactured Inconel 625 using gas tungsten arc welding. Mater Sci Eng A 676:395-405

18. Ma D, Stoica AD, Wang Z, Beese AM (2017) Crystallographic texture in an additively manufactured nickel-base superalloy. Mater Sci Eng A 684:47-53

19. Yadroitsev I, Thivillon L, Bertrand P, Smurov I (2007) Strategy of manufacturing components with designed internal structure by selective laser melting of metallic powder. Appl Surf Sci 254:980 983

20. Dewa R, Kim S, Kim W, Kim E (2016) Low cycle fatigue behaviors of alloy 617 (INCONEL 617) Weldments for high temperature applications. Metals 6:100

21. Sun S-H, Koizumi Y, Saito T, Yamanaka K, Li Y-P, Cui Y, Chiba A (2018) Electron beam additive manufacturing of Inconel 718 alloy rods: impact of build direction on microstructure and hightemperature tensile properties. Additive Manufacturing 23:457-470

22. Wege R, Wortmann J (1989) Properties of single-crystal alloys for turbine blades. Mat-wiss u Werkstofftech 20:207-216

23. Ghosh RN, Curtis RV, McLean M (1990) Creep deformation of single crystal superalloys - modelling the crystallographic anisotropy. Acta Metall Mater 38:1977-1992

24. Ziebs J, Klingelhöffe H, Meersmann J, Frenz H (1998) Gesetzmäßigkeiten für die werkstoffmechanische Beschreibung der einkristallinen Nickelbasislegierung SC 16 unter ein- und mehrachsiger Beanspruchung, Berlin

25. Haasen $P$ (1958) Plastic deformation of nickel single crystals at low temperatures. Philos Mag 3:384-418

Publisher's note Springer Nature remains neutral with regard to jurisdictional claims in published maps and institutional affiliations. 